\title{
The Importance of Critical Thinking, Verbal Reasoning and Mathematics in Teaching Chemistry in the $21^{\text {st }}$ Century
}

Laurie Gluck $^{1}$, Malinda Wilson Gilmore ${ }^{1 *}$ and Monica Dillihunt ${ }^{2}$

${ }^{1}$ Department of Physics, Chemistry and Mathematics, College of Engineering, Technology and Physical Sciences, Alabama Agricultural and Mechanical University, Normal, Al 35762, USA

${ }^{2}$ Department of Curriculum and Instruction, College of Education, University of Alabama in Huntsville, Huntsville, AL 35899, USA

"Corresponding author: Malinda Wilson Gilmore, Associate Professor of Chemistry, Department of Physics, Chemistry and Mathematics, Alabama Agricultural and Mechanical University, 4900 Meridian Street, Normal, Alabama 35762, USA, Tel: 256-372-4803; Fax: 256-372-8288; E-mail: malinda.gilmore@aamu.edu

Received date: July 08, 2015, Accepted date: July 09, 2015, Published date: July 13, 2015

Copyright: (c) 2015 Gluck L. This is an open-access article distributed under the terms of the Creative Commons Attribution License, which permits unrestricted use, distribution, and reproduction in any medium, provided the original author and source are credited.

\section{Editorial}

Chemistry is one of the most important courses a student will take in their secondary school years. It has been said that the concept of chemistry can be dated as far back as 500 to 300 B.C., as conveyed by Greek philosophers. Chemistry can date back even further to the times when making pottery, dyes, and metallurgy were in practice, although no known concepts have ever been recorded. Today, as the world becomes more technologically based, the need for an understanding of chemistry grows. Chemistry begins at the beginning of human life. Food, clothes, cars, and every other daily activity that humans participate in involve chemistry. By the time an individual reaches secondary school, the ability to comprehend and retain information about chemistry is present. It is essential for a student to be able to grasp the importance of critical thinking, verbal reasoning, and mathematics as it pertains to chemistry in the $21^{\text {st }}$ century. The knowledge of these three things can help the student to realize why the processes that take place in chemistry are present. As the National Council on Teacher Quality agrees, teachers must be licensed in the content area; which requires training in content as well as pedagogy in addition to the passing of qualification exams before teaching a course [1]. A qualified teacher is essential for the students to grasp the concepts of chemistry. Teachers are one of the most significant variables for upholding excellence and comprehension in education [1].

Critical thinking is a key component in many courses in secondary school, specifically chemistry. Critical thinking in the area of chemistry requires students to not just think about the concepts and principles of but also how they can be applied to other areas. Critical thinking creates an area of overlapping or related information to the nature of a certain function. In chemistry, the overlapping or related information can help a student to better understand the specific nature of a certain theory, function, formula or equation as it pertains to other information. Thinking critically involves logic, depth, clarity, and accuracy. Collecting data and drawing a conclusion from specific data is the result of the essential need and use of critical thinking. In chemistry, collecting data and drawing a conclusion is the basis for most experiments. Therefore, critical thinking is an imbedded concept in learning chemistry. A student that has not been taught this skill will find it difficult to draw appropriate conclusions in chemistry courses. Given that a conclusion that is drawn with critical thinking uses facts and facts prove conclusions and are therefore much more reliable; the process of creating and performing an experiment is useless if the conclusions that are drawn are not correct or from the facts of that particular experiment. A conclusion that is drawn with critical thinking also gives the student a chance to defend their conclusion.
With technology at students' fingertips, critical thinking is becoming a thing of the past. However, critical thinking is an important aspect to not only chemistry, but life. It helps individuals to think for themselves. Schools, teachers, and students are all too often worried about the correct answer and not about what an individual might think if they were not so concerned with making the passing grade. In science, there is not always a right or wrong answer. Critical thinking helps to explain why an individual came to a certain conclusion, whether others disagree or agree. According to Key, it does not matter how qualified a teacher is or the vast number of instructional strategies used, unless those strategies are ones that can help aid the student achieve the understanding of chemistry. Therefore, the ability for a student to critically think is imperative in chemistry [2].

Although it is imperative in chemistry for a student to have the ability to think critically, critical thinking is not the only important skill essential for overall success in chemistry. Critical thinking and verbal reasoning go hand in hand. Verbal reasoning is amongst one of the greatest skills a person can possess. Verbal reasoning allows an individual to understand concepts that are painted by words. Logic is used frequently in verbal reasoning, making it important in chemistry. Although much of chemistry and other sciences are clear cut, there are experiments and areas that require more explanations. Verbal reasoning can help an individual to explain their outcome of an experiment or the conclusion that is drawn. Verbal reasoning allows an argument to be brought forth to defend the individual's position and since science is not always black and white, the ability to reason can be very important. As Gustin points out, standardized tests such as the SAT, include an entire section testing one's ability on verbal reasoning [3]. Verbal ability is linked to better achievement in science than any other subject according to Gustin's experimental conclusion [3]. Verbal reasoning is one of the most difficult concepts to understand. It has been said that many people are either able to verbally reason or not. Teaching a student to use verbal reasoning is even more difficult, even from a highly qualified teacher. However, every individual must strive to do their best to use verbal reasoning and implement a great tool in the concepts of chemistry [3].

Chemistry is a bridge to many other natural sciences. It is, for that reason, no surprise that mathematics plays a huge role in chemistry. As Quinn states, mathematic skills can be transferred to science courses [4]. Chemistry is filled with math. Constants, temperatures, equations, and time are all parts of chemistry that require mathematics. Skills such as rounding, order of operations, and scientific notation are all essential to the basic properties of chemistry. Reading graphs and calculating slope, as would be done in a course such as geometry, is also a mathematic skill that is frequently used in 
chemistry. In laboratory experiments, making substances requires mathematic skills such as time, temperature, and measuring. If one of those variables is incorrect, especially when handling dangerous chemicals, a disaster could occur. In many cases, imaginary numbers, logarithms, and complex numbers have never been taught to students. Another large problem, at least for students in the United States, is the use of the metric system in chemistry. The metric system is the only system used in many other countries. However, in the United States, the metric is not the only system that is used. Students find great difficulty when having to convert measurements to metric units. This presents a problem to student in chemistry courses as those are mathematical skills that are frequently used in chemistry. The ability for a student to be able to use their mathematics knowledge for chemistry is crucial for the student to succeed in chemistry. Math skills also boost students' confidence levels in science classes since much of the science class is based on math. Chemistry without mathematics is impossible. The need for students to be able to use critical thinking, verbal reasoning, and mathematics all together in chemistry courses is a great reason that new teaching methods are best implemented by qualified chemistry teachers [4].

Chemistry is a difficult subject to comprehend and an even more complicated subject to teach. The quality of a teacher and the success of a student can be directly related. A qualified teacher can lead students to understanding the subject matter while an unqualified teacher may be unable to explain the reasoning behind many concepts of chemistry. Many secondary school students have a preconceived idea that chemistry is a course that will be difficult. Teachers who are not qualified to teach chemistry can make this fear a reality. Teachers provide students with the necessary tools that are required to succeed in their class. Teachers who are equipped with the qualifications for the course they are teaching are more effective in their teaching methods than those teachers who are not qualified to teach a course. Lackluster teaching methods, understanding mathematics, and poor knowledge of the laws and concepts of chemistry can lead students to have poor performance in an unqualified teacher's class. Understanding the content matter and knowledge of the basic principles of chemistry enable a teacher to successfully convey the subject matter of chemistry in secondary schools to their students. Students, in turn, are successful in the course and may take a further interest in chemistry. As Lu states, highly qualified teachers, especially in the areas of science are severely understaffed [5]. A qualified teacher has an interest in a particular subject and is therefore, more likely to be enthusiastic about teaching the course. This also makes the teacher more apt to make sure that the students understand the material fully and ensure that the students are receiving the correct information. The benefit of a qualified chemistry teacher is extremely important to the success of secondary school students [5].

It is extremely unfortunate that all schools are unable to provide students with qualified chemistry teachers. It is even more unfortunate that more students are not being adequately taught because of a lack of qualified educators. A qualified teacher is an effective teacher. Content knowledge, certification in a particular area, wide-ranging academic capability and teaching experience are all essential to being an effective teacher. A teacher who can interest their students in the subject matter of their course provides students with lifelong tools, especially in a chemistry course. Students who are taught by a qualified teacher also comprehend the importance of mathematics, critical thinking, and verbal reasoning in chemistry. Daily life events such as cooking, cleaning and the use of technology all implement chemistry in one way or another. Even the basic understanding of chemistry can help an individual to grasp the concept of how things in everyday life work. Further than daily life activities, a student may choose to advance their education into a field of chemistry if a teacher is able to spark the student's interest. Qualified teachers can help students to overcome any hesitations the student may have about chemistry or other higher sciences. The advancement of education in chemistry can lead to more qualified educators, technological advancements, or advancements of medicine. As the numerous branches of chemistry expand, the opportunities that arise from the advance understanding of chemistry are vast and all begin with a basic understanding and interest in a student's secondary school education [6].

\section{References}

1. National Council on Teacher Quality (2010) The All-Purpose Science Teacher: An Analysis of Loopholes in State Requirements for High School Science Teachers.

2. Kee TP, Ryder J (2014) Developing critical and communication skills in undergraduates through chemistry. Critical Skills Workshop.

3. Gustin WC, Corazza L (1994) Mathematical and verbal reasoning as predictors of science achievement. Roeper Rev 16: 160-162.

4. Quinn R (2014) Students' confidence in the ability to transfer basic math skills in introductory physics and chemistry courses at a community college. Dissertation Abstracts International Section A, 74 Center for Science and Math Education.

5. Lu X, Shen J, Poppink S (2007) Are Teachers Highly Qualified? A National Study of Secondary Public School Teachers Using SASS 1999-2000. Leadersh Policy Sch 6: 129-152.

6. Ozyalcin OO, Emine E, Ayhan Y (2009) Pre-Service Chemistry Teachers' Beliefs about Teaching and Their Pedagogical Content Knowledge. Hacettepe University J Educ 36: 36203-212. 